Review

\title{
Long-term effects of therapeutic exercise on nonspecific chronic neck pain: a literature review
}

\author{
Chin-Hsiu Cheng ${ }^{1,2)}$, Hao-Tsung Su ${ }^{1)}$, Ling-Wei Yen ${ }^{1)}$, Wen-Yu Liu'1), Hsin-Yi Kathy Cheng ${ }^{3)^{*}}$ \\ 1) Department of Physical Therapy and Graduate Institute of Rehabilitation Science, College of \\ Medicine, Chang Gung University, Taiwan \\ 2) Healthy Aging Research Center, Chang Gung University, Taiwan \\ 3) Graduate Institute of Early Intervention, College of Medicine, Chang Gung University: T No.259, \\ Wen-Hwa 1st Rd, Kweishan, Taoyuan, Taiwan
}

\begin{abstract}
Purpose] Nonspecific neck pain is a common musculoskeletal disease. Therapeutic exercise has been shown to improve pain and disability in short-term and midterm follow-ups. This study performed a literature review of the long-term effects of therapeutic exercise on subjects with nonspecific chronic neck pain. [Subjects and Methods] The databases of the CINAHL, MEDLINE, PEDro and PubMed were used. Randomized controlled trials (RCT) published from January 2000 to January 2014 and explicitly including a one-year follow-up were identified. [Results] Only six articles were included in this review. They had scores of 5 to 8 points on the PEDro scale, and the level of evidence was grade I. The study results show that the main exercises used were cervical strengthening and endurance training exercise. Short-term exercises (10 to 12 weeks) helped to improve the body function, structure, activity and participation immediately after the intervention, but not at the long-term follow-up. On the other hand, long-term interventions (1 year) resulted in improvements in body function and structure at the 3 year follow-up. [Conclusion] The results of the six high-quality studies suggest that long-term exercise have long-term benefits for patients with nonspecific neck pain in terms of body function and structure.

Key words: Nonspecific neck pain, Therapeutic exercise, Long-term effect
\end{abstract}

(This article was submitted Sep. 30, 2014, and was accepted Nov. 28, 2014)

\section{INTRODUCTION}

Neck pain is a common musculoskeletal disorder, and its economic cost is increasing in modern society. Many people work for a long time on monotonous tasks and consequently suffer from chronic neck pain. The life and work of the worker is usually affected, which leads to a tremendous economic burden due to healthcare costs at a national level, and chronic neck is of a great concern for public health. In North America and Europe, the problem is expected to account for approximately $0.5 \%$ to $2 \%$ of gross national product ${ }^{1)}$. The prevalence of neck pain has increased steadily over the past 20 years ${ }^{2,3)}$. More than $50 \%$ of adults have experienced neck pain within the past 6 months. Hoy ${ }^{4)}$ indicated in a systematic literature review that the one-year incidence of neck pain was between $10.4 \%$ and $21.3 \%$, and the one-year prevalence ranged from $4.8 \%$ to $79.5 \%$ (mean, $25.8 \%$ ). Women are more likely to experience persistent neck pain than men. The prevalence in women, $27.2 \%$, is higher than in men, $17.4 \%$.

\section{*Corresponding author. Hsin-Yi Kathy Cheng (E-mail:} kcheng@mail.cgu.edu.tw)

C2015 The Society of Physical Therapy Science. Published by IPEC Inc. This is an open-access article distributed under the terms of the Creative Commons Attribution Non-Commercial No Derivatives (by-ncnd) License $<$ http://creativecommons.org/licenses/by-nc-nd/3.0/>.
Nonspecific neck pain is a common type of neck pain that is induced by nonspecific musculoskeletal diseases. Such diseases may occur repeatedly, resulting in a vicious cycle of chronic pain (pain persisting for more than 3 months). Numerous studies have investigated the treatment of chronic nonspecific neck pain with interventions such as manual therapy, movement therapy, and physical therapy. Systematic reviews have indicated that there is abundant evidence verifying the therapeutic benefits of multiple therapies (mobilization combined with supervisory movement intervention $)^{5)}$. Moreover, movement therapy can effectively improve the short- and medium-term pain and disabilities of patients with chronic nonspecific neck pain ${ }^{6}$. However, the long-term (6 months or longer) effectiveness of movement therapy remains unknown. Thus, the objective of this study was to conduct a systematic review to verify the long-term therapeutic effectiveness of clinical movement therapy for patients with chronic nonspecific neck pain.

\section{SUBJECTS AND METHODS}

Studies from January 2000 to January 2014 found on four online databases and search engines, the Cumulative Index to Nursing and Allied Health Literature, MEDLINE, Physiotherapy Evidence Database [PEDro], and PubMed, were collected using the following key words: (a) nonspecific neck pain and neck pain; (b) exercise and training; and (c) long-term follow-up. 
The selection criterion for the studies was that they were randomized controlled trials (RCTs) in English. The patient inclusion criterion was chronic nonspecific neck pain persisting for more than 3 months. Patients with diagnosed neck diseases, such as nerve root compression, spinal cord compression, fracture, and infection, were excluded ${ }^{6}$. The intervention methods were the exercise training of the neck muscles, excluding whole-body exercise (e.g., qigong and yoga), physical factors, manual therapy, traction therapy, and drug treatment. The long-term follow-up reviewed by this study was defined as taking place at least 1 year after the baseline evaluation.

The quality of the literature was assessed using the PEDro Scale, a scale that is used to assess the evidence strength of therapeutic research. The PEDro Scale consists of 11 items and possesses reliability and validity. The total score ranges from 0 to 10 points. Studies with high, medium, and low quality are accredited 6 points or more, $4-5$ points, and 3 points or less, respectively ${ }^{7}$. On the basis of the Oxford Centre for Evidence-Based Medicine (OCEBM) Levels of Evidence, studies were classified as Levels 1 to 5 according to the research design structure. The highest evidence level (Level 1) was observed in the systematic literature review of $\mathrm{RCTs}^{8)}$.

In the present study, the researcher extracted the patient inclusion criteria, the number of patients, intervention methods and time, therapeutic effectiveness assessments, and outcomes of various studies. The therapeutic effectiveness and outcomes were classified based on the construction of International Classification of Functioning, Disability and Health include: (a) body function and structure, including muscular strength, range of motion, pain, and pressure pain threshold; and (b) activity and participation, including the Neck Disability Index, Health-Related Quality of Life, FearAvoidance Beliefs Questionnaire, and self-reported working ability (Fig. 1).

\section{RESULTS}

After a comprehensive search of the databases, six studies were included ${ }^{9-14)}$. Tables 1 and 2 detail the PEDro Scale scores and summarize of the studies. The six RCT studies ranked Level 1 on the OCEBM Levels of Evidence (1b, individual RCT). The PEDro Scale Items 5 and 6 regarding blinding strategies for patients and therapists could seldom be scored because of the varied exercise intervention meth- ods. The studies were scored as follows: one study was given 8 points $^{12)}$, four studies were given 7 points ${ }^{9-11,14)}$, and one study was given 5 points ${ }^{13}$. Five studies were high-quality and one was medium-quality. In the 5-point study, participants were randomly divided into various groups to create a baseline for the demographic data of the participants in each group. Thus, this study did not receive points for Item 2 (random allocation) and Item 7 (blinding setting) ${ }^{13)}$.

\section{Subjects}

Among the six studies, two used the same source of participants ${ }^{10,14)}$, but the assessment items of therapeutic effectiveness differed. Thus, these two studies were still included in the literature review. A total of 876 patients were obtained after excluding the same source of participants. All patients were diagnosed as having chronic nonspecific neck pain, and were aged between 37.9 and 45.6 years. Three of the studies focused on female patients $\left.{ }^{10,13}, 14\right)$, in whom the pain ranged from mild to moderate.

The therapeutic methods primarily included exercise training for muscle strength and endurance ${ }^{9-14}$. Other intervention methods included relaxation ${ }^{11,12)}$, coordination ${ }^{13)}$,

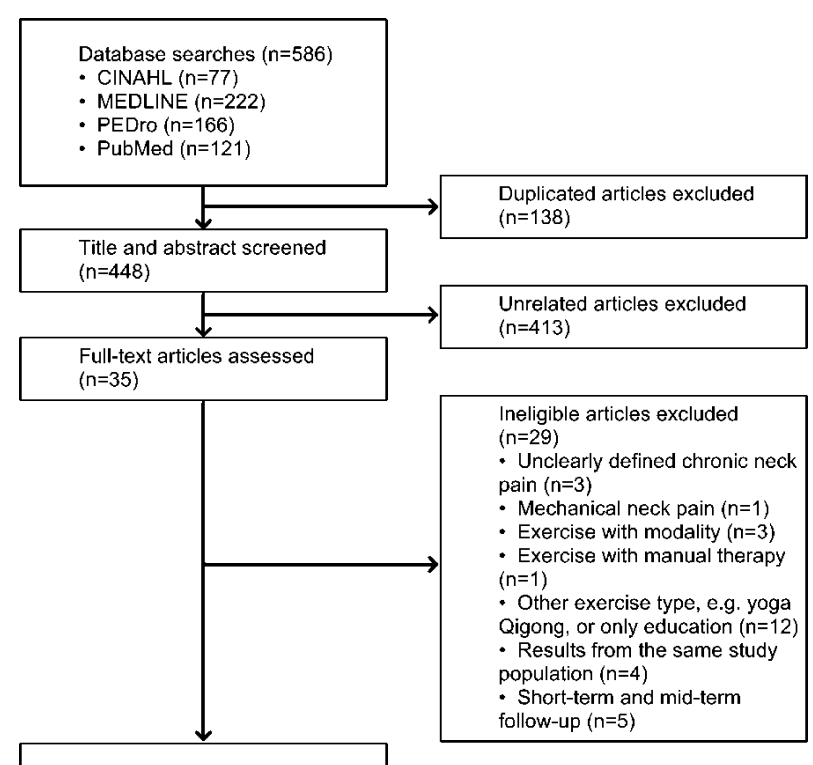

Articles included in this study $(n=6)$

Fig. 1. Flowchart of the selection of articles

Table 1. PEDro and Oxford Centre for Evidence-based Medicine Levels of Evidence of the included articles

\begin{tabular}{|c|c|c|c|c|c|c|c|c|c|c|c|c|c|}
\hline \multirow{2}{*}{ Article } & \multicolumn{12}{|c|}{ PEDro } & \multirow{2}{*}{$\begin{array}{l}\text { Levels of } \\
\text { Evidence* }\end{array}$} \\
\hline & 1 & 2 & 3 & 4 & 5 & 6 & 7 & 8 & 9 & 10 & 11 & Total & \\
\hline Ylinen et al. 200714) & Yes & Yes & No & Yes & Yes & No & No & Yes & Yes & Yes & Yes & $7 / 10$ & $\mathrm{Ib}$ \\
\hline Salo et al. $2010^{10)}$ & Yes & Yes & No & Yes & Yes & No & Yes & Yes & No & Yes & Yes & $7 / 10$ & $\mathrm{Ib}$ \\
\hline Salo et al. 2012 ${ }^{9)}$ & Yes & Yes & No & Yes & No & No & Yes & Yes & Yes & Yes & Yes & $7 / 10$ & $\mathrm{Ib}$ \\
\hline Taimela et al. $2000^{11)}$ & Yes & Yes & No & Yes & No & No & Yes & Yes & Yes & Yes & Yes & $7 / 10$ & $\mathrm{Ib}$ \\
\hline Viljanen et al. 2003 ${ }^{12)}$ & Yes & Yes & Yes & Yes & No & No & Yes & Yes & Yes & Yes & Yes & $8 / 10$ & $\mathrm{Ib}$ \\
\hline Waling et al. 2002 & Yes & No & No & Yes & No & No & No & Yes & Yes & Yes & Yes & $5 / 10$ & $\mathrm{Ib}$ \\
\hline
\end{tabular}

* Oxford Centre for Evidence-based Medicine Levels of Evidence 
Table 2. Summary of the included articles

\begin{tabular}{|c|c|c|c|c|}
\hline Study & Subjects & Intervention & Outcome & Results \\
\hline $\begin{array}{l}\text { Ylinen } \\
\text { et al. } \\
2007^{14)}\end{array}$ & $\begin{array}{l}180 \text { women with } \\
\text { chronic ( }>6 \text { month) } \\
\text { nonspecific neck } \\
\text { pain } \\
\text { Average age: } 45.6 \\
\text { Strength group: } \\
\mathrm{n}=60 \\
\text { Endurance group: } \\
\mathrm{n}=60 \\
\text { Control group: } \\
\mathrm{n}=60\end{array}$ & $\begin{array}{l}\text { Strength and endurance group rehabbed in center } \\
\text { for } 12 \text { days, and home exercise for } 12 \text { months, } 3 \\
\text { times a week. Total training time of } 12 \text { months } \\
\text { Strength group: } 80 \% \text { maximum isometric neck } \\
\text { resistance training with elastic rubber band in } \\
\text { sitting, a single series of } 15 \text { repetitions; dynamic } \\
\text { exercise with } 2 \text { kg-dumbbell: shrugs, press, curls, } \\
\text { bent-over rows, flies, pullovers for } 15 \text { repetitions; } \\
\text { squats, sit-ups, and back extension exercises; } \\
\text { stretching exercises for neck shoulder and upper } \\
\text { limb muscles; total exercise time of } 1 \text { hour } \\
\text { Endurance group: lifting head up in supine posi- } \\
\text { tion in } 3 \text { series of } 20 \text { repetitions; dynamic exercise } \\
\text { as above with } 3 \text { series of } 20 \text { repetitions; squats, } \\
\text { sit-ups, and back extension exercises; stretching } \\
\text { exercise; total exercise time of } 45 \text { minutes } \\
\text { Control group: stretching exercise was performed } \\
\text { once and subjects were asked to practice at home } \\
\text { for } 20 \text { minutes regularly } 3 \text { times a week }\end{array}$ & $\begin{array}{l}\text { (1) Pain-visual ana- } \\
\text { logue scale (VAS) } \\
\text { (2) Disability-Neck } \\
\text { disability index (NDI) } \\
\text { (3) Strength-handheld } \\
\text { isometric strength } \\
\text { testing device } \\
\text { (4) Passive cervi- } \\
\text { cal range of motion } \\
\text { (ROM) -multidimen- } \\
\text { sional neck ROM } \\
\text { device } \\
\text { (5) Pressure pain } \\
\text { threshold (PPT)- } \\
\text { handheld electronic } \\
\text { pressure algometer } \\
\text { Follow-up: } 12 \text { months } \\
\text { (all groups) and } 36 \\
\text { months (no control } \\
\text { group) }\end{array}$ & $\begin{array}{l}\text { - At 12-month follow- } \\
\text { up, all outcomes of the } \\
\text { strength and endurance } \\
\text { groups had improved } \\
\text { more than the control } \\
\text { group } \\
\text { - Pain, disability, PPT } \\
\text { of both training groups } \\
\text { and strength of the } \\
\text { endurance group im- } \\
\text { proved at the } 12-\text {-month } \\
\text { follow-up compared to } \\
\text { baseline, and the value } \\
\text { were unchanged at } 36 \\
\text { months. However, there } \\
\text { was no difference be- } \\
\text { tween the strength and } \\
\text { endurance groups }\end{array}$ \\
\hline $\begin{array}{l}\text { Salo } \\
\text { et al. } \\
2010^{10)}\end{array}$ & $\begin{array}{l}\text { Same as Ylinen et } \\
\text { al. } 2007^{14)}\end{array}$ & Same as Ylinen et al. 2007 & $\begin{array}{l}\text { (1) Quality of life- } \\
\text { health-related quality } \\
\text { of life (HRQoL): 15D } \\
\text { questionnaire } \\
\text { Follow-up: } 12 \text { months }\end{array}$ & $\begin{array}{l}\text { - Strength and endur- } \\
\text { ance of the exercise } \\
\text { groups were greater } \\
\text { than control group at } \\
\text { the } 12 \text {-month follow-up }\end{array}$ \\
\hline $\begin{array}{l}\text { Salo } \\
\text { et al. } \\
2012^{9)}\end{array}$ & $\begin{array}{l}\text { From Ylinen et al. } \\
2007 \text {, } \\
101 \text { chronic }(>6 \\
\text { month) nonspecific } \\
\text { neck pain patients } \\
\text { Average age: } 40.5 \\
\text { Strength group: } \\
n=49 \\
\text { Control group: } n=52\end{array}$ & $\begin{array}{l}\text { Strength group: same as the strength group above } \\
\text { Control group: same as the control group above }\end{array}$ & $\begin{array}{l}\text { (1) Quality of life- } \\
\text { health-related qual- } \\
\text { ity of life (HRQoL): } \\
\text { RAND-36 } \\
\text { Follow-up: } 12 \text { months }\end{array}$ & $\begin{array}{l}\text { - No difference be- } \\
\text { tween groups at the } \\
\text { 12-month follow-up }\end{array}$ \\
\hline $\begin{array}{l}\text { Taimela } \\
\text { et al. } \\
2000^{11)}\end{array}$ & $\begin{array}{l}76 \text { chronic }(>3 \\
\text { month) nonspecific } \\
\text { neck pain patients } \\
\text { Average age: } 43.7 \\
\text { Strength group: } \\
\mathrm{n}=21 \\
\text { Home exercise } \\
\text { group: } \mathrm{n}=19 \\
\text { Control group: } \mathrm{n}=22\end{array}$ & $\begin{array}{l}\text { Strength group: cervicothoracic stabilization } \\
\text { training, muscle relaxation training, behavioral } \\
\text { exercise, eye fixation exercise, seated wobble- } \\
\text { board training, total: } 45 \text { minutes, } 2 \text { times a week } \\
\text { for } 12 \text { weeks } \\
\text { Home exercise group: a lecture on neck pain and } \\
\text { written information about neck exercise with two } \\
\text { practices in small groups } \\
\text { Control group: a lecture on neck pain and written } \\
\text { information about neck exercise }\end{array}$ & $\begin{array}{l}\text { (1) Pain-VAS } \\
\text { (2) Fear avoidance } \\
\text { beliefs } \\
\text { (3) Cervical mobility- } \\
\text { goniometer } \\
\text { (4) PPT on upper } \\
\text { trapezius and levator } \\
\text { scapulas- mechanical } \\
\text { force gauge } \\
\text { (5) Self-experienced } \\
\text { working ability } \\
\text { Follow-up: } 3 \text { and } 12 \\
\text { months }\end{array}$ & $\begin{array}{l}\text { - At 3rd month, pain of } \\
\text { the } 2 \text { exercise groups } \\
\text { was lower than in the } \\
\text { control group, also } \\
\text { PPT of the } 2 \text { exercise } \\
\text { group higher than in the } \\
\text { control group. } \\
\text { - No group differences } \\
\text { at } 12 \text { months } \\
\text { - Self-experienced } \\
\text { working ability of the } \\
\text { strength group was } \\
\text { higher than in the } \\
\text { other groups at } 3 \text { and } 12 \\
\text { months }\end{array}$ \\
\hline
\end{tabular}


Table 2. Continued

\begin{tabular}{|c|c|c|c|c|}
\hline Study & Subjects & Intervention & Outcome & Results \\
\hline $\begin{array}{l}\text { Viljanen } \\
\text { et al. } \\
2003^{12)}\end{array}$ & $\begin{array}{l}393 \text { chronic }(>3 \\
\text { month) nonspecific } \\
\text { neck pain patients } \\
\text { Average age: } 45 \\
\text { Dynamic muscle } \\
\text { training group: } \mathrm{n}= \\
135 \\
\text { Relaxation training } \\
\text { group: } \mathrm{n}=128 \\
\text { Control group: } \\
\mathrm{n}=130\end{array}$ & $\begin{array}{l}30 \text { minutes a time, } 3 \text { times a week for } 12 \text { weeks } \\
\text { group training } \\
\text { (10 patients) } \\
\text { Dynamic muscle training group: training neck } \\
\text { and shoulder muscles with dumbbells (weight } \\
1-3 \mathrm{~kg} \text { ) and stretching exercise } \\
\text { Relaxation training group: progressive relaxation } \\
\text { method, autogenic training, functional relaxation } \\
\text { and systematic desensitization } \\
\text { Control group: no intervention }\end{array}$ & $\begin{array}{l}\text { (1) Pain- Numeric Rat- } \\
\text { ing Scale (NRS) } \\
\text { (2) Disability-NDI } \\
\text { (3) Cervical range of } \\
\text { motion-inclinometer } \\
\text { (4) Dynamic muscle } \\
\text { strength } \\
\text { Follow-up: } 3,6 \text { and } 12 \\
\text { months }\end{array}$ & $\begin{array}{l}\text { - Cervical side bend- } \\
\text { ing and rotation of } \\
\text { the } 2 \text { training groups } \\
\text { was larger than in the } \\
\text { control group at } 3,6 \text { and } \\
12 \text { months }\end{array}$ \\
\hline $\begin{array}{l}\text { Waling } \\
\text { et al. } \\
2002^{13)}\end{array}$ & $\begin{array}{l}126 \text { chronic trape- } \\
\text { zius myalgia } \\
\text { Average age: } 37.9 \\
\text { Strength group: } \\
\mathrm{n}=34 \\
\text { Endurance group: } \\
\mathrm{n}=34 \\
\text { Coordination group: } \\
\mathrm{n}=31 \\
\text { Control group: } \mathrm{n}=27\end{array}$ & $\begin{array}{l}\text { Exercise training for } 1 \text { hour a time, } 3 \text { times a } \\
\text { week for } 10 \text { weeks } \\
\text { Strength group: neck and shoulder exercise with } \\
10 \text { to } 12 \text { maximal voluntary contractions in three } \\
\text { sets } \\
\text { Endurance group: arm-cycling and arm exercise } \\
\text { with rubber band ( } 30 \mathrm{RM}=\text { repetition maximum) } \\
\text { Coordination group: body awareness training } \\
\text { Control group: stress management, once a week, } 2 \\
\text { hours a time, for } 10 \text { weeks }\end{array}$ & $\begin{array}{l}\text { (1) Neck and shoulder } \\
\text { pain-VAS } \\
\text { (2) Frequency of pain } \\
\text { (3) PPT-Somedic pres- } \\
\text { sure algomter } \\
\text { Follow-up: } 10 \text { weeks, } \\
\text { and } 8,17 \text { and } 36 \\
\text { months }\end{array}$ & $\begin{array}{l}\text { - Pain reduced and PPT } \\
\text { increased in all train- } \\
\text { ing groups at } 10 \text { weeks } \\
\text { compared to baseline } \\
\text { - No difference be- } \\
\text { tween training groups } \\
\text { and control group at } 8 \\
\text { months } \\
\text { - At } 36 \text { months, no } \\
\text { difference between the } \\
\text { training groups and } \\
\text { dropout subjects }\end{array}$ \\
\hline
\end{tabular}

and home training ${ }^{11)}$. Each study included a control group for comparison. Muscle strength exercises focused on training neck muscle strength using an elastic band in a sitting posture $^{9,10,14)}$, and muscle strength of the shoulders, neck, and upper body using dumbbells ${ }^{9-11,13,14)}$, combined with traction exercise $\mathrm{e}^{9,10,12,14)}$ and whole-body exercise ${ }^{9,10,14)}$. The endurance exercises focused on training for the muscular endurance of the shoulders and neck, such as lifting the head from the bed when in a lying position ${ }^{6,7,11)}$, and using an arm-cranking machine and elastic bands. Participants in the control group did not engage in the exercise interventions, traction exercise, or perform basic home exercise.

Exercise intervention was divided into short-term intervention $(10-12 \text { weeks })^{11-13)}$ and long-term intervention (1 year $)^{9,10,14)}$. Regardless of the intervention duration, the intervention frequency ranged from 2 to 3 times a week. Each exercise session lasted between 45 and 60 minutes.

In all the studies, the outcomes of various exercise training groups did not show significant differences. However, those of the exercise groups and control groups differed substantially, indicating that the exercise groups improved more than the control groups. The effects of the various exercises were similar, but the intervention duration had dissimilar therapeutic effectiveness and is discussed below. After short-term interventions (10-12 weeks, 2-3 times a week, 45-60 minutes per session), the body function and structure of patients in the exercise groups substantially improved compared to the control groups. For example, exercise group patients reported reduced pain, an increased pressure pain threshold ${ }^{11,13)}$, and increased neck mobility. In addition, regarding the activity and social participation, patients reported improved ability at work ${ }^{12)}$. However, the body structure and function of the exercise and control groups at the 1 year long-term follow up did not differ significantly ${ }^{11-13)}$. As for the long-term interventions (1 year, 3 times per week, 60 minutes per session), the body structure and function of the patients in the exercise groups substantially improved compared to their respective control groups. For example, the patients with long-term intervention showed reduced pain, a reduced level of disability, enhanced neck muscular strength, increased passive activity of the neck, and an increased pressure pain threshold ${ }^{14)}$. In terms of the activity and social participation, the patients with long-term intervention showed improved quality of life ${ }^{10)}$; however, the quality of life subscale score pertaining to the neck did not differ from that of the control group ${ }^{9)}$. The longterm follow up of the exercise group revealed that the body structure and function of the exercise groups, such as neck pain, disability, and pressure pain threshold, did not differ at the 3 year and 1 year follow up. Nevertheless, the follow-up results indicated substantial improvements compared with the baseline performance ${ }^{14}$.

\section{DISCUSSION}

This systematic review revealed that when patients with chronic nonspecific neck pain performed muscle strength and endurance training for the neck as a primary exercise intervention, the efficacy of the various exercise methods differed little. However, after short-term exercise intervention (10-12 weeks), the body structure and function, and activity and social participation improved immediately, albeit, only for a short period of time. Long-term exercise intervention (1 year) improved body structure and function, 
and the improvement persisted for 3 years.

Studies included in this systematic review were all RCTs, each of which recruited enough participants and featured specific inclusion criteria. The drop-out rates of participants also remained within the regulated range specified on the PEDro Scale. However, because the intervention was exercise training, a double-blind design was unlikely to be adopted. Overall, the included studies yielded high levels of evidence and included medium-to-high quality research, with sufficient representative evidence.

Because the inclusion criteria for the participants in all studies were specifically regulated, the homogeneity across the studies was high. It should be noted that patients with upper trapezius pain were also recruited ${ }^{13)}$ since their condition satisfied the criteria of nonspecific neck pain. Bertozzi et $\mathrm{al}^{6}{ }^{6}$. also adopted the same criteria in their systematic report. Therefore, patients experiencing upper trapezius pain were included in this review.

The exercise interventions included in this systematic review consisted primarily of neck muscle strength and endurance training. The exercise training in all studies conformed to common training protocols. For example, the muscle strength training was performed with high intensity and low repetition. The muscle strength training of the shoulders and neck consisted of 10 to 12 maximal voluntary contractions per set performed for three sets ${ }^{13}$. Elastic bands were used to perform $80 \%$ maximal voluntary isometric contraction of the neck for 15 repetitions ${ }^{14)}$. The endurance training was performed with low intensity and high repetition. The endurance exercises included lifting the head from a bed in the lying position, training upper body muscles by lifting $2-\mathrm{kg}$ dumbbells 20 times per set for three sets ${ }^{14)}$. Arm-cranking machines were also used to improve endurance ${ }^{12}$. Other therapies had similar therapeutic effectiveness. Enhanced relaxation training and behavioral therapy programs could be provided for subjects depending on personal traits. However, the duration of the intervention might lead to differences in the effectiveness of long-term therapies. Ylinen's long-term exercise training was performed for 12 months. After training in a rehabilitation center for 12 days, the subjects independently performed home training for 12 months. Ylinen et al. monitored the exercise progress at the end of the second, sixth, and twelfth months. The participants exercised an average of 1.9 times per week. The reason exercise effectiveness persisted for 3 years could be because patients had cultivated an exercise habit or that they independently engaged in short-term home training in response to neck pain ${ }^{14)}$.

Diverse training exercises, such as yoga and qigong, have been used for treating nonspecific neck pain. Previous studies have reported that experimental groups performing in qigong reported reduced levels of neck pain and disability and higher quality of life compared to their respective control groups. In addition, the therapeutic effectiveness of qigong was similar to that of movement therapy, yielding no significant statistical differences ${ }^{15)}$. However, the present review focused on regular therapies that can be provided by physical therapists in clinical environments and the studies related to qigong were excluded.

Only six studies were included and three of them origi- nated from the same research team ${ }^{6,7,11)}$, which extended the large-scale research of Ylinen et al. In addition, the outcomes of two studies by Salo were immediately assessed when the intervention concluded. That is, the two studies had a long-term follow-up of 1 year and the intervention period was 1 year as well. Therefore, follow-up of subsequent effectiveness was lacking, enabling no further information about the follow-up changes in quality of life after the long-term intervention $\left.{ }^{9}, 10\right)$. Only one long-term follow-up study of three years pertaining to long-term exercise was included. Further studies are required to validate the long-term therapeutic effectiveness of exercise on activity and social participation $^{14)}$.

The studies reviewed in this study were medium- or high-quality RCTs with high evidence reliability. The reviewed results show that short-term neck exercise training yields immediate therapeutic relief for patients with chronic nonspecific neck pain. However, their effectiveness was not sustained for long. When the patients developed long-term exercise habits at home, the body structure and function of the patients improved with concomitant long-term benefits. More high-level evidence is needed to verify the efficacy of long-term exercise interventions on patients' activity and social participation.

\section{ACKNOWLEDGEMENTS}

This research was supported by the Ministry of Science and Technology (101-2221-E-182-020-MY3), and the Chang Gung Memorial Hospital Research Program (CMRPD1D0121).

\section{REFERENCES}

1) Kilbom S, Armstrong T, Buckle P, et al.: Musculoskeletal disorders: workrelated risk factors and prevention. Int J Occup Environ Health, 1996, 2: 239-246. [Medline] [CrossRef]

2) Cheng $\mathrm{CH}$, Cheng HY, Chen $\mathrm{CP}$, et al.: Altered co-contraction of cervical muscles in young adults with chronic neck pain during voluntary neck motions. J Phys Ther Sci, 2014, 26: 587-590. [Medline] [CrossRef]

3) Kanchanomai $S$, Janwantanakul P, Jiamjarasrangsi W: One-year incidence and risk factors of thoracic spine pain in undergraduate students. J Phys Ther Sci, 2013, 25: 15-20. [CrossRef]

4) Hoy DG, Protani M, De R, et al.: The epidemiology of neck pain. Best Pract Res Clin Rheumatol, 2010, 24: 783-792. [Medline] [CrossRef]

5) Tsakitzidis G, Remmen R, Dankaerts W, et al.: Non-specific neck pain and evidence-based practice. ESJ, 2013, 9: 1857-7881.

6) Bertozzi L, Gardenghi I, Turoni F, et al.: Effect of therapeutic exercise on pain and disability in the management of chronic nonspecific neck pain: systematic review and meta-analysis of randomized trials. Phys Ther, 2013, 93: 1026-1036. [Medline] [CrossRef]

7) Centre of Evidence-Based Physiotherapy: Physiotherapy evidence database scale. http://www.pedro.org.au. (Accessed May 1, 2003)

8) Oxford Centre for Evidence-based Medicine - Levels of Evidence: http:// www.cebm.net/?O=1025. Updated March 2009. (Accessed May 1, 2013)

9) Salo P, Ylönen-Käyrä N, Häkkinen A, et al.: Effects of long-term homebased exercise on health-related quality of life in patients with chronic neck pain: a randomized study with a 1-year follow-up. Disabil Rehabil, 2012, 34: 1971-1977. [Medline] [CrossRef]

10) Salo PK, Häkkinen AH, Kautiainen $H$, et al.: Effect of neck strength training on health-related quality of life in females with chronic neck pain: a randomized controlled 1-year follow-up study. Health Qual Life Outcomes, 2010, 8: 48. [Medline] [CrossRef]

11) Taimela $S$, Takala EP, Asklöf $T$, et al.: Active treatment of chronic neck pain: a prospective randomized intervention. Spine, 2000, 25: 1021-1027. [Medline] [CrossRef] 
12) Viljanen M, Malmivaara A, Uitti J, et al.: Effectiveness of dynamic muscle training, relaxation training, or ordinary activity for chronic neck pain randomised controlled trial. BMJ, 2003, 327: 475. [Medline] [CrossRef]

13) Waling K, Järvholm B, Sundelin G: Effects of training on female trapezius Myalgia: an intervention study with a 3-year follow-up period. Spine, 2002, 27: 789-796. [Medline] [CrossRef]
14) Ylinen J, Häkkinen A, Nykänen $M$, et al.: Neck muscle training in the treatment of chronic neck pain: a three-year follow-up study. Eura Medicophys, 2007, 43: 161-169. [Medline]

15) Rendant D, Pach D, Lüdtke R, et al.: Qigong versus exercise versus no therapy for patients with chronic neck pain: a randomized controlled trial. Spine, 2011, 36: 419-427. [Medline] [CrossRef] 